\title{
The Value of Umbilical Cord Blood Bilirubin Measurement in Predicting the Development of Significant Hyperbilirubinemia in Healthy Newborn
}

\author{
ZAKIA NAHAR ${ }^{1}$, MD. SHAHIDULLAH ${ }^{2}$, ABDUL MANNAN $^{3}$, SANJOY KUMAR DEY $^{4}$, UJJAL MITRA $^{5}$, \\ SM SELIMUZZAMAN ${ }^{6}$
}

\begin{abstract}
The present study was conducted to investigate the predictability of early serum bilirubin levels on the subsequent development of neonatal hyperbilirubinemia. For this purpose 84 healthy newborn infants were enrolled and followed up for first 5 days of life. Study subjects were divided into two groups. Group-I consisted of 71 subjects, who did not develop significant hyperbilirubinemia (bilirubin $<17 \mathrm{mg} / \mathrm{dl}$ ); Group-II consisted of 13 newborns, who developed significant hyperbilirubinemia (bilirubin $>17$ $\mathrm{mg} / \mathrm{dl})$ during the follow up. Of the enrolled subjects, 46 (55\%) were male and rest 38 (45\%) were female; 64 (76\%) were term babies and 20 (24\%) were pre-term babies. Significantly higher percentage of pre-term babies developed hyperbilirubinemia. ROC (receiver operating characteristic) analysis demonstrates that the critical value of cord blood bilirubin $>2.5 \mathrm{mg} / \mathrm{dl}$ had the high sensitivity (77\%) and specificity (98.6\%) to predict the newborn who would develop significant hyperbilirubinemia. At this level the negative predictive value was $96 \%$ and positive predictive value $91 \%$. In our setting infants having umbilical cord blood total serum bilirubin (TSB) $>2.5 \mathrm{mg} / \mathrm{dl}$ should be followed up strictly either in hospital or as an outpatient department on day 5 if practicable. Infants having TSB $<2.5 \mathrm{mg} / \mathrm{dl}$ in cord blood can be discharged early.
\end{abstract}

Key words: Umbilical cord bilirubin, neonatal jaundice, healthy newborn.

\section{Introduction}

Jaundice is the visible manifestation in skin and sclera of elevated serum concentration of bilirubin. Neonatal jaundice may not appear until serum bilirubin exceeds 5 to $7 \mathrm{mg} / \mathrm{dl}$. Any serum total bilirubin (STB) elevation exceeding $17 \mathrm{mg} / \mathrm{dl}(291 \mu \mathrm{mol} / \mathrm{l})$ is considered pathologic and warrants investigations for a cause and possible therapeutic intervention ${ }^{1}$. Neonatal hyperbilirubinaemia is a cause of concern for the parents, and paediatricians as well. It occurs in 5-

1. Assistant Professor (Neonatology), Department of Paediatrics (Neonatal Unit), Sir Salimullah Medical College, Dhaka

2. Chairman, Department of Neonatology, Bangabandhu Sheikh Mujib Medical University, Dhaka

3. Associate Professor, Department of Neonatology, Bangabandhu Sheikh Mujib Medical University, Dhaka

4. Assistant Professor (Neonatology), Dhaka Medical College, Dhaka

5. Junior Consultant (Paediatrics), Dhaka Medical College Hospital, Dhaka

6. Instructor, Department of Physiology, Armed Forces Medical Institute, Dhaka Cantonment, Dhaka

Correspondence: Dr. Zakia Nahar
$10 \%$ of healthy term infants ${ }^{2}$. Neonatal hyperbilirubinaemia is the most common reason of readmission after early hospital discharge. Concerns regarding jaundice have increased after reports of bilirubin induced brain damage occurring in healthy term infants even without haemolysis ${ }^{3,4}$. Early discharge of healthy term newborns after delivery has become a common practice, because of medical and social reasons and economic constrains ${ }^{5}$. Thus, the recognition, follow up and early treatment of jaundice has become more difficult as a result of early discharge from the hospital. Severe jaundice and even kernicterus can occur in some full term healthy newborns discharged early with no apparent early findings of haemolysis ${ }^{4}$.

The American Academy of Pediatrics recommends that newborns discharged within 48 hours should have a follow up visit after 2-3 days for any significant jaundice and other problems 6 . This recommendation is not appropriate for our country due to limited follow up facilities in the community. Therefore, it is difficult 
to predict which infants are at increased risk for significant and relatively late hyperbilirubinaemia. And as such, from the obvious need to design and implement a follow up programme, the present study was conducted to find out the critical value of serum bilirubin in the cord blood in predicting the subsequent development of hyperbilirubinemia in healthy newborn.

\section{Materials and Methods}

This prospective study was conducted between June 2006 to May 2007 in the Neonatal Unit, Department of Paediatrics in collaboration of the Department of Gynaecology and Obstetrics, Bangabandhu Sheikh Mujib Medical University (BSMMU). Among all healthy term and near term newborns delivered consecutively in the Department of Gynaecology and Obstetrics, 100 healthy infants of $>35$ weeks gestation (based on last menstrual period and neonatal assessment by expanded new Ballard Score) with an APGAR score $>7$ at $5 \mathrm{~min}$, were enrolled purposively for the study. Newborn babies demonstrating Rh incompatibility or any congenital anomaly were excluded from the study. The babies requiring neonatal intensive care unit (NICU) admission and or showing any complication that could aggravate the hyperbilirubinaemia, e.g., neonatal sepsis were also excluded from the study.

Informed written parental consent was taken before enrolling the baby into the study. After enrolment, relevant information from history, physical findings and laboratory investigations were recorded on a predesigned questionnaire. Permission was also taken from the concerned departmental ethical committee.

Umbilical cord blood samples were collected from all newborns who complied with the inclusion criteria. Collected blood samples were investigated for complete blood count (CBC), blood film, blood grouping including Rhesus factor, direct anti-globulin test and serum direct and indirect bilirubin. The infants were followed up clinically every day till discharge. The subjects were motivated to come for follow up after discharge at 5 days of age or early if the parents found their baby significantly icteric for clinical assessment and for rechecking of serum bilirubin. Serum bilirubin was repeated on $5^{\text {th }}$ day. Serum bilirubin was measured by using Colorimetric Method - DMSO by auto analyzer (Eos Bravo). Newborns with serum total bilirubin level $>17 \mathrm{mg} / \mathrm{dl}$ after 72 hours of life was defined to have significant hyperbilirubinaemia.

Study subjects were divided into two groups. Group-I consisted of 71 subjects, who did not develop significant hyperbilirubinemia $(<17 \mathrm{mg} / \mathrm{dl})$; Group-II consisted of 13 newborns, who developed significant hyperbilirubinemia (>17 mg/dl) during the follow-up. Group-I and II were further divided into sub groups IA, IIA; and IB, IIB depending upon the time of sampling. In sub-group $A$, blood samples were collected from umbilical cord; in sub-group B, venous blood samples were taken on day 5 .

Data were processed and analyzed by using Statistical Package for Social Sciences 12 (SPSS 12) soft ware for Windows. Data were expressed as mean $\pm S D$ and percentage. To compare mean values between groups, t-test and $\chi^{2}$ test were applied as appropriate. $P<0.05$ was considered as minimum level of significance. The serum bilirubin level measured in the cord blood having the highest sensitivity for predicting subsequent hyperbilirubinemia was determined with the receiver operating characteristic (ROC) curve analysis.

\section{Results}

Out of one hundred initially enrolled new born babies seven did not comply with follow-up schedule, parents of five babies withdrew from the study and four others were admitted in NICU (neonatal intensive care unit) for severe sepsis and were excluded from the study, thus drop out rate was about $16 \%$. A total of 84 subjects were followed up for the first five days of life with clinical assessment and laboratory investigations.

Of the enrolled subjects, 46 (55\%) were male and rest 38 (45\%) were female; 64 (76\%) were term babies and 20 (24\%) were pre-term babies. All newborns were exclusively breast fed. Of the term babies, 6 (9.4\%) developed hyperbilirubinemia and significantly higher percentage (35\%) of pre-term infants (7 out of 20) developed hyperbilirubinemia. Gestational age of the subjects was observed to have significant effect on hyperbilirubinemia in group II $\left(\chi^{2}=5.816\right.$; $\mathrm{P}$ $<0.05)$ (Table-I).

Table-I

Distribution of gestational age of the study subjects between groups

\begin{tabular}{|c|c|c|c|c|c|c|}
\hline \multirow[t]{2}{*}{ Gestational Age } & \multirow[t]{2}{*}{$\mathrm{n}$} & \multirow{2}{*}{$\begin{array}{c}\text { Group-I } \\
\text { N (\%) }\end{array}$} & \multirow{2}{*}{$\begin{array}{l}\text { Group-II } \\
\text { N (\%) }\end{array}$} & \multicolumn{3}{|c|}{ Group-I vs. Group-II } \\
\hline & & & & $\mathrm{df}$ & $\chi^{2}$ value & $P$ value \\
\hline Full-term (>37 weeks) & 64 & $58(90.6)$ & $6(9.4)$ & 1 & 5.816 & .016 \\
\hline Pre-term (<37 weeks) & 20 & $13(65)$ & $7(35)$ & & & \\
\hline
\end{tabular}


A total of 71 (84.5\%) subjects went back home at day 6 uneventfully with satisfactory outcome and did not develop significant hyperbilirubinemia. These babies were comprised as Group I. The mean ( $\pm \mathrm{SD}$ ) serum total bilirubin in cord blood, and on day 5 of the babies in this group were $1.8( \pm 0.3) \mathrm{mg} / \mathrm{dl}$ and $11.3( \pm 2.1) \mathrm{mg} /$ dl respectively. During follow-up period, 13 (15.5\%) babies developed significant hyperbilirubinemia (TSB $>17 \mathrm{mg} / \mathrm{dl}$ ) and appropriate therapeutic intervention was offered. These babies were comprised as Group II and had a mean $( \pm S D)$ total serum bilirubin in umbilical cord blood, and on fifth day of life were 2.7 $( \pm 0.3) \mathrm{mg} / \mathrm{dl}$ and $17.8( \pm 0.8) \mathrm{mg} / \mathrm{dl}$ respectively.
Mean $( \pm S D)$ total and indirect serum bilirubin in cord blood and on day 5, was significantly higher in Group II in comparison to Group I (Group IA vs. IIA, and IB vs. IIB) with $P$ value $<0.001$. But these differences for direct bilirubin is only significant at cord blood bilirubin (IA vs. IIA; $\mathrm{P}<0.05$ ) (Table-II).

ROC (receiver operating characteristic) analysis (Fig.-1) demonstrates that cord blood bilirubin $>2.5 \mathrm{mg} / \mathrm{dl}$ had the high sensitivity (77\%) and specificity (98.6\%) to predict the newborn that would develop significant hyperbilirubinemia. At this level the negative predictive value was $96 \%$. The critical cut off value for the development of hyperbilirubinemia is $>2.5 \mathrm{mg} / \mathrm{dl}$.

Table-II

Mean $( \pm S D)$ serum bilirubin concentration with statistical significance in different groups of subjects

\begin{tabular}{|c|c|c|c|c|c|c|c|}
\hline Group & $\mathrm{n}$ & \multicolumn{2}{|c|}{$\begin{array}{l}\text { Serum total bilirubin } \\
\text { (TSB) }(\mathrm{mg} / \mathrm{dl})\end{array}$} & \multicolumn{2}{|c|}{$\begin{array}{c}\text { Serum direct } \\
\text { Bilirubin (mg/dl) }\end{array}$} & \multicolumn{2}{|c|}{$\begin{array}{c}\text { Serum indirect } \\
\text { Bilirubin (mg/dl) } \\
\text { Mean ( } \pm \mathrm{SD})\end{array}$} \\
\hline IA & 71 & \multicolumn{2}{|c|}{$1.8( \pm 0.3)$} & \multicolumn{2}{|c|}{$0.6( \pm 0.1)$} & \multicolumn{2}{|c|}{$1.2( \pm 0.3)$} \\
\hline IB & 71 & \multicolumn{2}{|c|}{$11.3( \pm 2.1)$} & \multicolumn{2}{|c|}{$1.21( \pm 1.2)$} & \multicolumn{2}{|c|}{$10.1( \pm 2.2)$} \\
\hline$\| A$ & 13 & \multicolumn{2}{|c|}{$2.7( \pm 0.3)$} & \multicolumn{2}{|c|}{$0.8( \pm 0.4)$} & \multicolumn{2}{|c|}{$1.8( \pm 0.4)$} \\
\hline IIB & 13 & \multicolumn{2}{|c|}{$17.8( \pm 0.8)$} & \multicolumn{2}{|c|}{$1.1( \pm 0.3)$} & \multicolumn{2}{|c|}{$16.6( \pm 0.8)$} \\
\hline Group & df & t value & $\mathrm{P}$ value & $\mathrm{t}$ value & $P$ value & $\mathrm{t}$ value & $P$ value \\
\hline IA vs. IIA & 82 & -10.38 & $.000^{* \star \star}$ & -2.36 & $0.035^{\star}$ & -7.11 & $.000^{\star * \star}$ \\
\hline IB vs. IIB & 82 & -18.95 & $.000^{\star \star \star}$ & .19 & .847 & -19.01 & $.000^{\star \star *}$ \\
\hline
\end{tabular}

${ }^{*} \mathrm{P}<0.05{ }^{* *}=\mathrm{P}<0.01 ;{ }^{* \star *}=\mathrm{P}<0.001$

Table-III

Sensitivity, specificity, and positive and negative predictive values of various cord blood bilirubin levels in predicting the development of significant hyperbilirubinemia

\begin{tabular}{lcccccccc}
\hline Bilirubin level 2 mg/dl & TP & FN & FP & TN & Sn & Sp & PPV & NPV \\
\hline $2.5 \mathrm{mg} / \mathrm{dl}$ & $10(11.9 \%)$ & $3(3.5 \%)$ & $1(1.19 \%)$ & $70(83.3 \%)$ & .77 & .98 & $91 \%$ & $96 \%$ \\
$3 \mathrm{mg} / \mathrm{dl}$ & $4(4.7 \%)$ & $9(10.7 \%)$ & $0(.0 \%)$ & $71(84.5 \%)$ & .31 & 1.0 & $100 \%$ & $88.75 \%$ \\
\hline
\end{tabular}

TP - true positive; FN - false negative; FP - false positive; TN - true negative; Sn - sensitivity, Sp - specificity; PPV positive predictive value; NPV - negative predictive value 


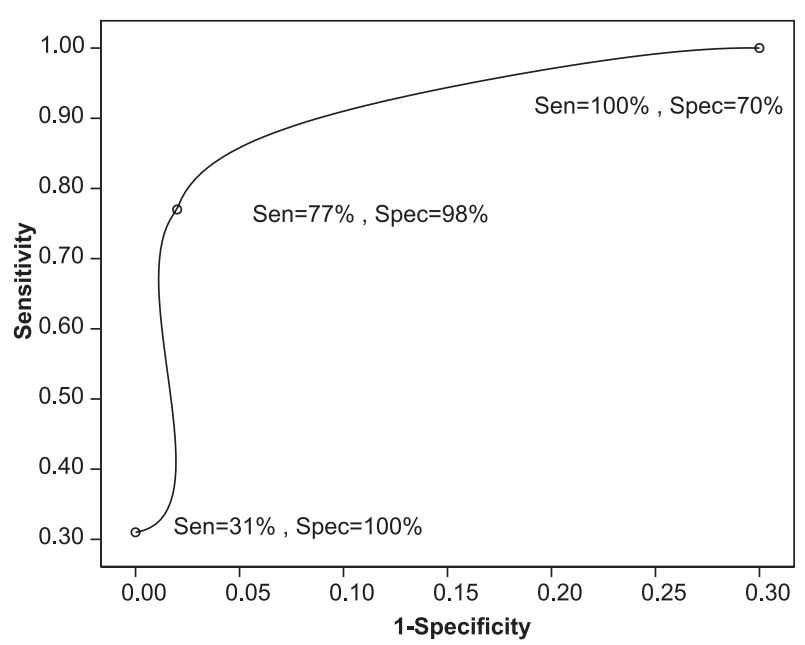

Fig.-1: The ROC analysis of the various bilirubin levels in cord blood in predicting the development of subsequent- hyperbilirubinemia.

\section{Discussion}

Debate and dilemma continue to pass on regarding length of stay in the hospital, safety and risk of early discharge from hospital, framing a follow-up schedule benefiting each country considering her health resources and economic constrain, attitude in the community etc. Thus, from the long felt desire of framing up of our own follow-up programme and to investigate out the predictability of early bilirubin measurements on subsequent hyperbilirubinemia, the present study was conducted.

In the present study, a total 64 (76.2\%) newborn babies out of 84 were full term and rest $20(23.8 \%)$ were preterm babies. Of the full-term babies 6 (9.4\%) developed significant hyperbilirubinemia, whereas among the preterm babies, $7(35 \%)$ developed significant hyperbilirubinemia. Gestational age of the subjects was observed to have significant effect on hyperbilirubinemia. Similar observation was made by Singhal et $\mathrm{al}^{2}(16.7 \%)$ and Narang et al $(47.9 \%)^{7}$. On the other hand, some researchers did not observe any significant effect of gestational age , $^{8,9}$.

In the present study in the Postnatal Ward of Gynae and Obstetrics Department of BSMMU, 13 of 84 (15.5\%) babies were found to have significant hyperbilirubinemia on $5^{\text {th }}$ day of follow-up. Narang et $\mathrm{al}^{7}$ also reported similar incidence (14.5\%). The incidence is relatively higher compared to observations of Singhal et $\mathrm{al}^{2}(5.9 \%)$. It may be due to smaller sample size. The mean ( $\pm S D$ ) serum bilirubin concentrations were significantly higher through out the whole period of observation in the subjects who developed significant hyperbilirubinemia (TSB $>17 \mathrm{mg} /$ dl) compared to those who did not develop hyperbilirubinemia. Similar observations were also reported by Bhutani et al ${ }^{10}$ in their predischarge hourspecific measurements of serum bilirubin.

In the umbilical cord blood samples, applying the critical value of $2.5 \mathrm{mg} / \mathrm{dl}$, demonstrated that $73(87 \%)$ infants had their serum total bilirubin concentrations $\leq 2.5 \mathrm{mg} / \mathrm{dl}$. Three of them (4.1\%) subsequently developed significant hyperbilirubinemia. Eleven newborns had serum total bilirubin $>2.5 \mathrm{mg} / \mathrm{dl}$ and 10 $(90.9 \%)$ of them developed significant hyperbilirubinemia. This critical value of $2.5 \mathrm{mg} / \mathrm{dl}$ had a negative and positive predictive value of $96 \%$ and $91 \%$ respectively with sensitivity $77 \%$ and specificity 98.59\%. Bernaldo and Segre ${ }^{11}$ investigated the predictability of umbilical cord blood unconjugated bilirubin concentration on subsequent hyperbilirubinemia and need for therapy. Utilizing a cut-off point of un-conjugated bilirubin of $2.0 \mathrm{mg} / \mathrm{dl}$, they showed that $53 \%$ babies needed phototherapy and raising the cut-off value to $2.5 \mathrm{mg} / \mathrm{dl}$ predicted that $72 \%$ babies need phototherapy.

\section{Conclusion}

Mean serum bilirubin concentrations were significantly higher in Group II subjects in comparison to Group I throughout the period of observation. Measurement of throughout TSB in umbilical cord blood has predictive value in identifying neonates who would develop significant hyperbilirubinemia warranting therapeutic intervention. Cut-off values of $2.5 \mathrm{mg} / \mathrm{dl}$ for umbilical cord blood can predict significant hyperbilirubinemia with high negative and positive predictive values and high levels of sensitivity and specificity. Use of the critical bilirubin level of $2.5 \mathrm{mg} / \mathrm{dl}$ in umbilical cord blood will predict nearly all healthy newborns who will have significant hyperbilirubinemia and will identify those infants who will require phototherapy later during first days of life. In our setting infants having umbilical cord blood TSB $>2.5 \mathrm{mg} / \mathrm{dl}$ should be followed up strictly either in hospital or as an outpatient department on day 5 if practicable. Infants having TSB $<2.5 \mathrm{mg} / \mathrm{dl}$ in cord blood can be discharged early.

\section{References}

1. Madan A, MacMahon JR, Stevenson DK. Neonatal Hyperbilirubinaemia. In: Taeusch HW, 
Ballard RA, Gleason CA, editors. Avery's disease of the newborn. $8^{\text {th }}$ ed. Philadelphia: Saunders; 2005. P. 1227-56.

2. Singhal PK, Singh M, Paul VK, Deorari AK, Ghorpade MG. Spectrum of neonatal hyperbilirubinemia: an analysis of 454 case. Indian Pediatr 1992; 29: 319-25.

3. Penn AA, Enzman DR, Han JS, Stevenson DK. Kernicterus in a full term infant. Pediatrics 1994; 93: 1003-06.

4. Maisels MJ, Newman TB. Kernicterus in otherwise healthy, breast-fed term newborns. Pediatrics 1995; 96: 730-33.

5. Norr KF, Naocin K. Outcomes of post partum early discharge, 1960-1986; a comparative review. Birth 1987; 14: 135-41.

6. American Academy of Pediatrics. Practice parameter: Management of hyperbilirubinemia in the healthy term newborn. Pediatrics 1994; 94 : 558-67.
7. Narang A, Gathwala G, Kumar P. Neonatal jaundice: an analysis of 551 cases. Indian Pediatr 1997; 34: 429-32.

8. Awasthi S, Rehman H. Early prediction of neonatal hyperbilirubinemia. Indian J Pediatr 1998; 65: 131-39.

9. Alpay F, Sarici SU, Tosuncuk HD, Serdar MA, Inanc N, Gökcay E. The value of first-day bilirubin measurement in predicting the development of significant hyperbilirubinaemia in healthy term newborns. Pediatrics 2000; 106: 16-21.

10. Bhutani VK, Johnson L, Sivieri EM. Predictive ability of a predischarge hour-specific serum bilirubin for subsequent significant hyperbilirubinaemia in healthy term and nearterm newborns. Pediatrics 1999; 103: 6-14.

11. Bernaldo AJN, Segre CA, de Mattos. Bilirubin dosage in cord blood: could it predict neonatal hyperbilirubinaemia? Sao Paulo Medical Journal 2004; 122: 99-103. 